\title{
Energy Savings Potential Associated with Reactive Power in Water Pumping Systems
}

\author{
Abdallah S. Hejab ${ }^{a}$ and Ahmad H. Sakhrieh ${ }^{b, c, *}$ \\ ${ }^{a}$ Head of Technical Studies, Research and Development, Water Authority of Jordan, 5012 Amman 11181, Jordan \\ ${ }^{b}$ Department of Mechanical and Industrial Engineering, American University of Ras Al Khaimah, 10021 UAE \\ ${ }^{c}$ Mechanical Engineering Department, University of Jordan, Amman 11942, Jordan
}

\begin{abstract}
This paper presents the potential of energy saving in water pumping system. A sample of 32 pumping units has been chosen randomly for the current work. Measurements of power quality energy loss were performed, using Fluke 437-ii power quality and energy analyzer. It was found that energy losses due to reactive power is about $22 \%$ of the total power energy losses in water pumping units in Jordan. Losses due to reactive power is $14.57 \mathrm{GWh}$ in 2012 with an expected cost of 51.2 GWh during 2015-2017; unless reactive power is cured.
\end{abstract}

Keywords: Energy Efficiency, Reactive Power, Water Pumping

\section{Introduction}

Water supply in Jordan relies mainly on resources, which are located at a considerable distance to agglomerations. Consequently, the water sector involves an energy extensive operation by deploying large water pumping, boosting and treatment and distribution facilities [1]. Power requirements only for water pumping in 2013 amounted to about $14 \%$ of the total power production of Jordan with a total amount of 2076 GWh [2].

Reassessing and anatomizing electricity use for water pumping highlights the study of energy efficiency and energy loss sources. One source of energy loss is due to poor power quality. Power quality determines the fitness of electric power to consumer devices. Mitigation of poor power quality issues has several outcomes beside energy savings, precisely, those related to system reliability, performance, maintenance, operation, and selection of water equipment.

Several researchers worked on energy efficiency and power quality problems. The effect of motor vibration problems on the dynamic performance and electrical power quality of water pumping stations was studied in Egypt [3]. Power quality and energy efficiency assessment and the need for labeling and

${ }^{*}$ Corresponding author

E-mail: ahmad.sakhrieh@aurak.ac.ae

(C) 2016 International Association for Sharing Knowledge and Sustainability

DOI: $10.5383 /$ ijtee.11.01.009 minimum performance standard of uninterruptible power systems in Brazil were studied [4]. It was found that an improvement of 5\% in efficiency for UPS units would result in an annual reduction of losses with a corresponding reduction in the power demand. A normalization/regression-based approach to estimate the $\mathrm{kWh}$ energy and $\mathrm{kW}$ savings from an experimental OEEP (operational energy-efficiency program) for municipal water pumping in California was implemented [5]. It was concluded that a program designed to improve municipal water pumping's operational energy efficiency requires targeted implementation, aiming at pump sites with known poor performance or pumps with variable operating regimes.

Energy audit for efficient water pumping system necessitates studying, identifying, and quantifying energy loss caused by power quality issues and the associated financial costs of such wastes. One of these issues is the reactive power. Reactive energy is the energy stored in inductors as a magnetic field or in capacitors as an electric field. Reactive energy does not cause losses itself. However, the reactive loss is the line power loss due to reactive system current.

Energy savings will have good impacts at the technical, economic, social, and environmental levels for Jordan. In this paper, energy loss caused by reactive power and the associated financial costs would be explored, examined, investigated, and applied for the water pumping sector in Jordan. 


\section{Problem Description}

The specific energy consumption for Jordan's water sector for the year 2013 was $7.2 \mathrm{kWh} / \mathrm{m}^{3}$ (billed) for the Water Authority of Jordan (WAJ), mainly for municipal water supply, 95\%, and wastewater, and $0.46 \mathrm{kWh} / \mathrm{m}^{3}$ (billed) for the Jordan Valley Authority (JVA), mainly for irrigation and industrial use in the Jordan Valley. The weighted average consumption for the public sector water facilities is $4.2 \mathrm{kWh} / \mathrm{m}^{3}[6]$.

Given that the water sector is highly subsidized, the total energy bill paid by Ministry of Water and Irrigation (MWI) (including JVA and WAJ) in 2013 was JOD 100 million, which is equivalent to an average specific power cost of $0.069 \mathrm{JOD} / \mathrm{kWh}$. However, this figure does not reflect the actual power costs paid by the Government. The actual power expenses amount to 0.189 JOD/kWh approximately [6].

This result in an actual energy bill of the year for the water sector JOD 270 million paid by the Government with a subsidized amount of JOD 170 million. Subsides pose a major additional obstacle to more efficient power consumption as they do not generate incentives for power saving. A more transparent accounting system to avoid double counting is required as well as creating a coherent one-subsidy point along the service chain to eliminate hidden subsidies [1].

Since the consumption of JVA constitutes a small portion compared to that of WAJ, the focus will mainly be on improving the energy consumption of WAJ facilities [1].

Before August 15, 2013, electricity tariff for water pumping in Jordan was 66 Fils per kWh. After that, Electricity Regularity Commission (ERC) has modified the tariff for all sectors and users through a plan for five years by increasing the tariff in steps, Table 1 summarizes water sector electricity tariff [7].

Table 1: Electricity Tariff for Water Sector in Jordan till Year 2017

\begin{tabular}{llccccc}
\hline Period & From & $15 / 08 / 2013$ & 2014 & 2015 & 2016 & 2017 \\
& Till & $31 / 12 / 2013$ & & & & \\
\hline Tariff & Fils/kWh & 76 & 87 & 100 & 115 & 133
\end{tabular}

The tariff for water pumping is a flat-rated penalty-free. For this reason, the electricity bill for water pumping sector is simple, i.e. complexity in calculating the peak demand and power factor penalties will not appear.

For every $\mathrm{kWh}$ consumption there is an additional tax equals one Fils, and it is dedicated to rural electrification projects. In this work the rural Fils will be added to the electricity tariff automatically to account for power quality fiscal costs, i.e. for the year 2015 the actual tariff will be 101 Fils.

The power system in Jordan's water sector is 4-wire three phase wye (y)-connected system. The active power for all frequency components, is directly calculated from the voltage (u) and current (i) inputs:

$P_{X}=\frac{1}{N} \sum_{n=K}^{K+N} u_{x}(n) \cdot i_{X}(n)$

where $\mathrm{P}_{\mathrm{x}}$ is the active phase power. System power is the sum of the phase powers.

The active system power is:

$\mathbf{P}_{\mathrm{Y}}=\mathbf{P}_{\mathrm{A}}+\mathbf{P}_{\mathrm{B}}+\mathbf{P}_{\mathrm{C}}$

The fundamental powers are concerning the first harmonics. These are Root Mean Square (RMS) values denoted as $\mathrm{U}_{1 \mathrm{X}}$ for voltage and $I_{1 x}$ for current. The phase angle between voltage and current is $\left(\varphi u_{1 x}-\varphi i_{1 x}\right)$. The fundamental active phase power is:

$P_{1 x}=U_{1 x} \cdot I_{1 x} \cdot \cos \left(\varphi u_{1 x}-\varphi i_{1 x}\right)$

However, the fundamental active system power is:

$P_{1}^{+}=3 \cdot U_{1}^{+} \cdot I_{1}^{+} \cos \left(\varphi u_{1}^{+}-\varphi i_{1}^{+}\right)$

In this case the system power is not the sum of the phase powers. The system power is calculated from the positive sequence components of voltage and current, eliminating all unbalance components. This component is also called Effective power as it is the most effective way to transfer power (electrical into mechanical) if it would only consist of the positive sequence power component.

The apparent power (all frequency components) is calculated from the RMS values of voltage $\mathrm{U}_{\mathrm{X}}$ and current $\mathrm{I}_{\mathrm{X}}$. The apparent phase power is:

$\mathbf{S}_{\mathbf{X}}=\mathbf{U}_{\mathbf{X}} \cdot \mathbf{I}_{\mathbf{X}}$

The apparent system power is not the sum of the phase powers. The apparent system power is:

$S_{Y}=\sqrt{\left(U_{A}^{2}+U_{B}^{2}+U_{C}^{2}\right) \cdot\left(I_{A}^{2}+I_{B}^{2}+I_{C}^{2}\right)}$

Fundamental apparent phase power is:

$S_{1 X}=U_{1 X} \cdot I_{1 x}$

Fundamental apparent system power is:

$S_{1 Y}^{+}=3 \cdot U_{1}^{+} \cdot I_{1}^{+}$

For reactive power only the fundamental power is of interest. Fundamental reactive phase power is:

$Q_{1 x}=U_{1 x} \cdot I_{1 x} \cdot \sin \left(\varphi u_{1 x}-\varphi i_{1 x}\right)$

System reactive power is not the sum of the phase powers. Fundamental reactive system power is:

$$
Q_{1}^{+}=3 \cdot U_{1}^{+} \cdot I_{1}^{+} \sin \left(\varphi u_{1}^{+}-\varphi i_{1}^{+}\right)
$$

For Jordan's water sector, pumping units are operating progressively over the time.

Comparing motor rated power and the measured power, reveals the improper selection of motor units to drive the pumps. However, the measured power is related directly to the head $(\mathrm{H})$ [m] and quantity (Q) $\left[\mathrm{m}^{3} / \mathrm{s}\right]$ of the pump according to the following equation:

$P=\frac{Q \times H \times g \times \rho}{\text { Pump Efficiency }}$

Where; $\rho=$ Density $\left(\mathrm{kg} / \mathrm{m}^{3}\right)$

However, practically, to select the appropriate motor power $[\mathrm{kW}]$; quantity $\left[\mathrm{m}^{3} / \mathrm{h}\right]$ and head $[\mathrm{m}]$ are multiplied by a factor equals 0.0045 , e.g. for $\mathrm{H}=200 \mathrm{~m}$ and $\mathrm{Q}=70 \mathrm{~m}^{3} / \mathrm{h} ; \mathrm{P}=63 \mathrm{~kW}$. The following equation is used to select pipe size, usually $2.5[\mathrm{~m} . \mathrm{s}]$ specific speed is used, e.g. for $70 \mathrm{~m}^{3} / \mathrm{h}$ flow rate the $4 "$ pipe is sufficient.

$V=\frac{Q}{A}$

Where; V= Velocity in the pipe $(\mathrm{m} / \mathrm{sec})$ $\mathrm{Q}=$ Flow rate through the pipe $\left(\mathrm{m}^{3} / \mathrm{sec}\right)$ $\mathrm{A}=$ Pipe cross sectional area $\left(\mathrm{m}^{2}\right)$ 


\section{Methodology}

In this paper, Fluke 437-ii is used to measure and analyze reactive power and energy consumption. Initial setup to the power quality and energy analyzer device, Fluke 437-ii, has been held to identify some parameters; including details of the electrical system, electricity tariff, and other measurement details.

A sample of 32 pumping units has been chosen randomly for the current work. Measurements of power quality energy loss were performed, using Fluke 437-ii power quality and energy analyzer. For each pumping unit; measurements have been stored and recorded. Power measurements included; the Energy loss calculator; the Scope, and the Logger. The Energy loss calculator summarizes the losses caused by power quality issues. The Scope is an oscilloscope option. The Logger is used to record predetermined parameters.
This paper concentrates on energy loss due to reactive loading. Data collected from these screens are sufficient to conduct the required analysis; however the Logger, the Scope, and other data are available for more elaboration on a situation. The tariff in the Energy loss calculator screen appears in two decimal points; however, it is actually in four decimal points as set previously. The scenario of increasing the power of the electrical motor was tested for the last two samples, $31 \& 32$. The procedure was as follows: First, a $60 \mathrm{~kW}$ motor was coupled to the 70/200 pump and measurements were conducted. Then, the $60 \mathrm{~kW}$ motor was replaced with $110 \mathrm{~kW}$, rising in the drawn current and more energy loss with the increased reactive power were noticed on the Energy loss screen.

\section{Discussion of Results}

The obtained results and the calculation for the reactive power losses from 32 different pumps are presented in Table 2.

Table 2: Reactive Power Loss Calculations

\begin{tabular}{|c|c|c|c|c|c|c|c|c|c|c|c|}
\hline \multirow{4}{*}{ 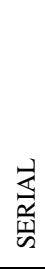 } & \multicolumn{4}{|c|}{ SPECIFICATIONS } & \multirow{2}{*}{\multicolumn{7}{|c|}{ REACTIVE ENERGY LOSS }} \\
\hline & \multicolumn{3}{|l|}{ Pump } & \multirow{2}{*}{$\begin{array}{l}\text { Motor } \\
\text { Power }\end{array}$} & & & & & & & \\
\hline & Type & Quantity & Head & & $\begin{array}{l}\text { Corrected } \\
\text { Tariff }\end{array}$ & $\begin{array}{l}\text { Energy } \\
\text { Loss } \\
\text { Screen }\end{array}$ & $\begin{array}{l}\text { Total } \\
\text { Power } \\
\text { Energy } \\
\text { Loss }\end{array}$ & $\begin{array}{l}\text { Reactive } \\
\text { Loss }\end{array}$ & $\begin{array}{l}\text { Modified } \\
\text { Reactive } \\
\text { Loss }\end{array}$ & $\begin{array}{l}\text { Reactive } \\
\text { Loss }\end{array}$ & $\begin{array}{l}\text { Reactive } \\
\text { Loss }\end{array}$ \\
\hline & Centrifugal & $\mathrm{m} 3 / \mathrm{h}$ & $\mathrm{m}$ & $\mathrm{kW}$ & $\mathrm{JOD} / \mathrm{kWh}$ & link & JOD/Y & $\mathrm{JOD} / \mathrm{h}$ & $\mathrm{JOD} / \mathrm{h}$ & $\mathrm{JOD} / \mathrm{Y}$ & $\%$ \\
\hline 1 & Horizontal & 250 & 350 & 400 & 0.101 & 1 & 11752.7 & 0.17 & 0.26 & 2278.93 & $19.39 \%$ \\
\hline 2 & Horizontal & 150 & 350 & 250 & 0.101 & 2 & 7273.5 & 0.08 & 0.12 & 1072.44 & $14.74 \%$ \\
\hline 3 & Horizontal & 250 & 350 & 400 & 0.101 & 3 & 11255.4 & 0.16 & 0.24 & 2144.87 & $19.06 \%$ \\
\hline 4 & Horizontal & 250 & 350 & 400 & 0.101 & 4 & 10263.7 & 0.15 & 0.23 & 2010.82 & $19.59 \%$ \\
\hline 5 & Horizontal & 150 & 250 & 200 & 0.101 & 13 & 5134.2 & 0.06 & 0.09 & 804.33 & $15.67 \%$ \\
\hline 6 & Horizontal & 250 & 350 & 400 & 0.101 & 14 & 10185.7 & 0.13 & 0.20 & 1742.71 & $17.11 \%$ \\
\hline 7 & Horizontal & 150 & 300 & 206 & 0.101 & 20 & 6378.3 & 0.07 & 0.11 & 938.38 & $14.71 \%$ \\
\hline 8 & Horizontal & 250 & 300 & 320 & 0.101 & 29 & 11927.2 & 0.22 & 0.34 & 2949.20 & $24.73 \%$ \\
\hline 9 & Horizontal & 350 & 300 & 440 & 0.101 & 8 & 9255.0 & 0.29 & 0.29 & 2540.40 & $27.45 \%$ \\
\hline 10 & Horizontal & 250 & 290 & 330 & 0.101 & 9 & 6882.0 & 0.18 & 0.18 & 1576.80 & $22.91 \%$ \\
\hline 11 & Horizontal & 250 & 290 & 330 & 0.101 & 19 & 7325.0 & 0.18 & 0.18 & 1576.80 & $21.53 \%$ \\
\hline 12 & Horizontal & 500 & 250 & 560 & 0.101 & 6 & 18100.0 & 0.35 & 0.35 & 3066.00 & $16.94 \%$ \\
\hline 13 & Horizontal & 500 & 250 & 560 & 0.101 & 16 & 16450.0 & 0.30 & 0.30 & 2628.00 & $15.98 \%$ \\
\hline 14 & Horizontal & 300 & 250 & 320 & 0.101 & 52 & 9191.0 & 0.24 & 0.24 & 2102.40 & $22.87 \%$ \\
\hline 15 & Horizontal & 300 & 250 & 320 & 0.101 & 59 & 9786.0 & 0.26 & 0.26 & 2277.60 & $23.27 \%$ \\
\hline 16 & Horizontal & 250 & 250 & 315 & 0.101 & 67 & 8062.0 & 0.20 & 0.20 & 1752.00 & $21.73 \%$ \\
\hline 17 & Horizontal & 200 & 250 & 225 & 0.101 & 69 & 6261.0 & 0.12 & 0.12 & 1051.20 & $16.79 \%$ \\
\hline 18 & Horizontal & 200 & 300 & 320 & 0.101 & 78 & 8334.0 & 0.17 & 0.17 & 1489.20 & $17.87 \%$ \\
\hline 19 & Submersible & 50 & 350 & 75 & 0.101 & 9 & 2627.0 & 0.06 & 0.06 & 525.60 & $20.01 \%$ \\
\hline 20 & Submersible & 50 & 350 & 75 & 0.101 & 29 & 2718.0 & 0.06 & 0.06 & 525.60 & $19.34 \%$ \\
\hline 21 & Submersible & 50 & 350 & 75 & 0.101 & 43 & 2388.0 & 0.06 & 0.06 & 525.60 & $22.01 \%$ \\
\hline 22 & Submersible & 50 & 350 & 75 & 0.101 & 74 & 2625.0 & 0.08 & 0.08 & 700.80 & $26.70 \%$ \\
\hline 23 & Submersible & 50 & 350 & 75 & 0.101 & 94 & 2496.0 & 0.07 & 0.07 & 613.20 & $24.57 \%$ \\
\hline 24 & Submersible & 50 & 350 & 75 & 0.101 & 100 & 2412.0 & 0.05 & 0.05 & 438.00 & $18.16 \%$ \\
\hline 25 & Submersible & 50 & 250 & 60 & 0.101 & 6 & 2170.0 & 0.05 & 0.05 & 438.00 & $20.18 \%$ \\
\hline 26 & Submersible & 50 & 100 & 22 & 0.101 & 16 & 639.4 & 0.03 & 0.03 & 262.80 & $41.10 \%$ \\
\hline 27 & Submersible & 50 & 125 & 30 & 0.101 & 23 & 873.5 & 0.04 & 0.04 & 350.40 & $40.11 \%$ \\
\hline 28 & Submersible & 100 & 50 & 37 & 0.101 & 30 & 1206.0 & 0.03 & 0.03 & 262.80 & $21.79 \%$ \\
\hline 29 & Submersible & 20 & 130 & 11 & 0.101 & 39 & 348.9 & 0.01 & 0.01 & 87.60 & $25.11 \%$ \\
\hline 30 & Submersible & 150 & 100 & 67 & 0.101 & 45 & 2093.0 & 0.05 & 0.05 & 438.00 & $20.93 \%$ \\
\hline 31 & Submersible & 70 & 200 & 60 & 0.101 & 7 & 2136.0 & 0.06 & 0.06 & 525.60 & $24.61 \%$ \\
\hline 32 & Submersible & 70 & 200 & 110 & 0.101 & 13 & 2510.0 & 0.10 & 0.10 & 876.00 & $34.90 \%$ \\
\hline
\end{tabular}


The actual power expenses for electrical power needed for water pumping is $95 \%$ of the value recorded for the MWI; i.e. $95 \%$ of $0.185 \mathrm{JOD} / \mathrm{kWh}$, which equals $0.18 \mathrm{JOD} / \mathrm{kWh}$. This percent also equals $1972.2 \mathrm{GWh}$. The average percent for energy loss caused by reactive power based on the sample equals $22.25 \%$ of power losses. Thus, the reactive loss for the year 2013 equals 16.83 GWh. CO2 emissions associated with this loss for the same year is equivalent to about 12.25 Million $\mathrm{kgCO}_{2}$. Considering a growth equals $4.22 \%$ in water sector consumption enables imagining the ongoing situation.

One cause of power factor reduction or increased losses through the reactive power is by increasing the power of the electrical motor. This scenario was tested for the last two samples, $31 \&$ 32. The procedure was as follows: First, a $60 \mathrm{~kW}$ motor was coupled to the 70/200 pump and measures were conducted. Then, the $60 \mathrm{~kW}$ motor was replaced with $110 \mathrm{~kW}$, rising in the drawn current and more energy loss with the increased reactive power were noticed. This is due to the high windage of the motor coils of the $110 \mathrm{~kW}$ unit.

Figure (1) shows the state of phase voltages for the first case, sample 31 .

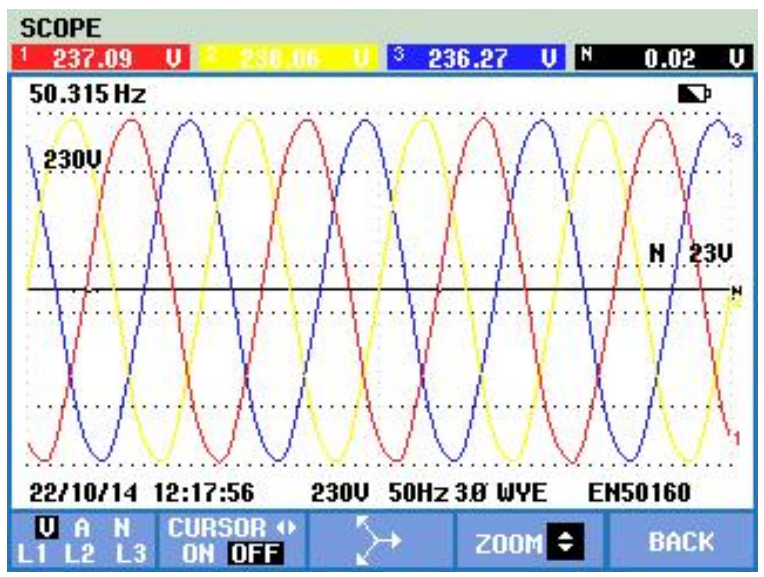

Fig. 1. Sample 31 Phase Voltage

The state of phase currents for the first case, sample 31 is shown in Figure (2). The distortion is obvious from this chart. The average phase current magnitude is $104.5 \mathrm{~A}$.

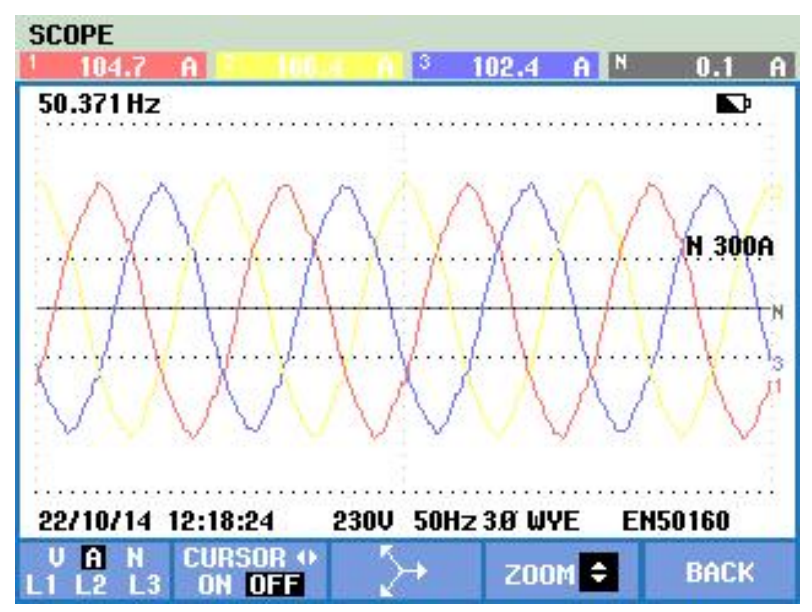

Fig. 2. Sample 31 Phase Current
The state of the neutral for the first case, sample 31 is shown in Figure (3). The negligible values point to the balance in phases.

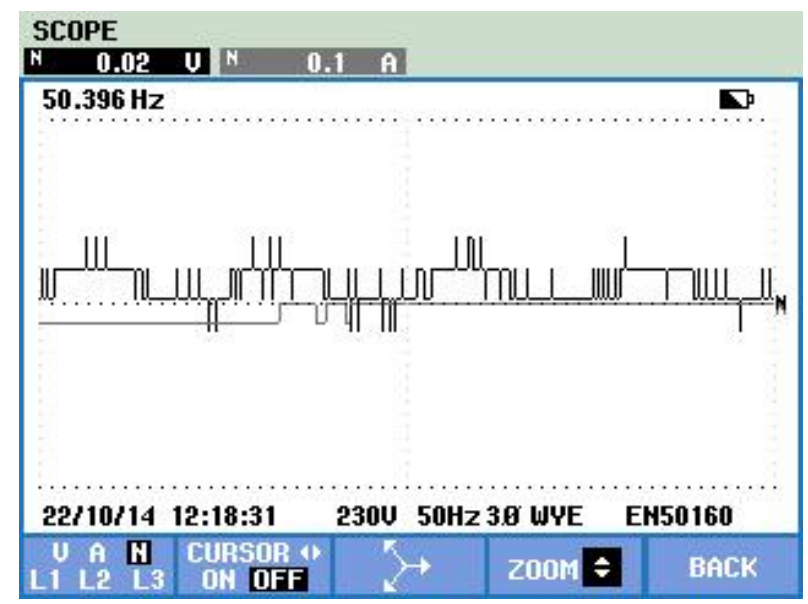

Fig. 3. The State of the Neutral for Sample 31

The phasor diagram of phase voltages for the first case, sample 31, is shown in Figure (4).

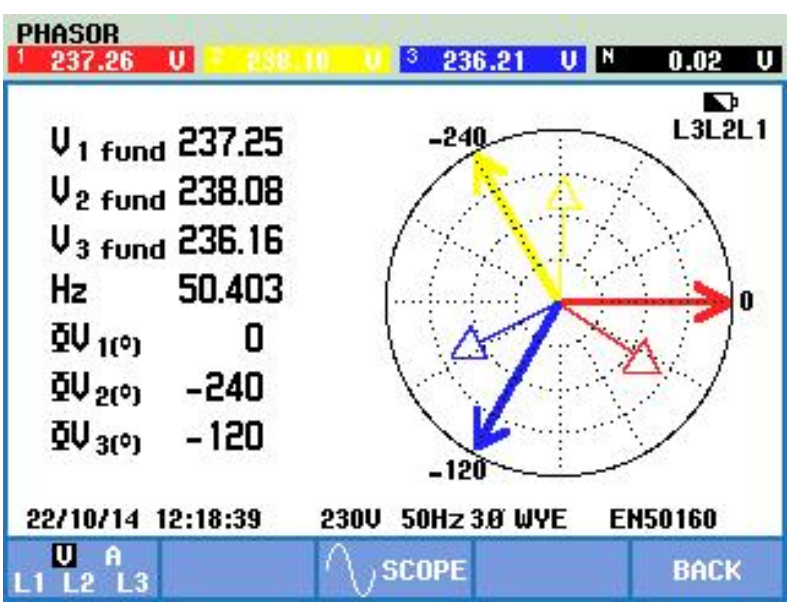

Fig. 4. Phase Voltage in Phasor Diagram for Sample 31

Figure (5) shows the state of phase currents in phasor diagram for the first case, sample 31. Notice the deviation of phase current angles from the angles of phase voltages. However, the measured $\mathrm{PF}$ equals 0.85 . 


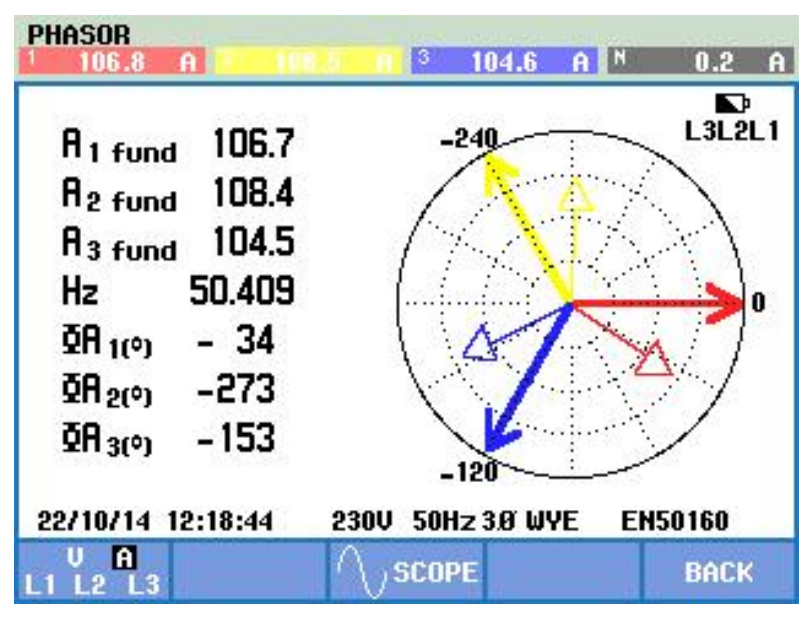

Fig. 5. Phase Current in Phasor Diagram for Sample 31

Figure (6) shows the power energy loss for the first case, sample 31. The percentage of reactive loss is $24.61 \%$. The same measurements were conducted for sample 32. Clearly, the distortion appears for all the studied electric motors. The average phase current is 135.87 A. This causes a $30 \%$ increase in the drawn current. The reactive power loss average for all studied pumps is about $22 \%$. The obtained results showed that the increased deviation of phase current angles from the angles of phase voltages leads to more reactive load. However, the measured PF is decreased to 0.70 .

\section{Conclusions}

Jordan's water pumping sector has more than 1000 working pumping units. In this research a sample of 32 pumping units was considered to study energy loss due to reactive power. It was found that about $22 \%$ of the losses due to poor power quality is associated with reactive power. The effect of improving energy consumption is directly related to environment. So improvising energy efficiency will reduce emitted gasses like $\mathrm{CO}_{2}$.

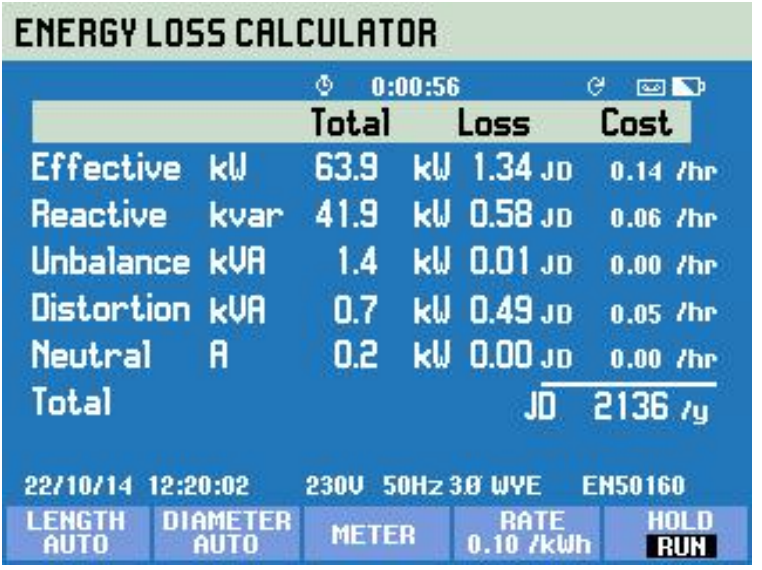

Fig. 6. Sample 31 State of Power Energy Loss

\section{References}

[1] Jordan's Ministry of Water and Irrigation, Energy Efficiency and Renewable Energy Policy for the Jordanian Water Sector.

[2] Jordan's Ministry of Energy and Mineral Recourses, Annual Report, 2013

[3] K. Fetyan, D. El Gazzar, Effect of motor vibration problem on the power quality of water pumping stations, Water Science 28 (2014) 31-41.

[4] Ildo L. Sauer, He' dio Tatizawa, Francisco A.M. Salotti, Power quality and energy efficiency assessment and the need for labelling and minimum performance standard of uninterruptible power systems (UPS) in Brazil, Energy Policy 41 (2012) 885-892.

[5] A. DeBenedictis, B. Haley, C.K. Woo, E. Cutter, Operational energy-efficiency improvement of municipal water pumping in California, Energy 53 (2013) 237-243.

[6] The Energy Situation in Jordan, Ministry of Planning and International Cooperation, Mojaheed Elsagheer, July 2013.

[7] Jordan's Electricity Regularity Commission, Annual Report (2013) 